\title{
DISCLOSING LEARNERS' BEHAVIOUR AND ENGAGEMENT INTO ONLINE AND BLENDED COURSES: CASE STUDY OF VYTAUTAS MAGNUS UNIVERSITY
}

Giedré Tamoliūnè, Margarita Teresevičienè, Vytautas Magnus University, Lithuania, Josep M. Duart, Universitat Oberta de Catalunya, Spain, Justina Naujokaitienè, Vytautas Magnus University, Lithuania

\section{Abstract}

Interfaces between students' participation, number of submissions to discussion forums, attendance of online lectures and students' performance on their assignments are significant for students' success and achievements. Teachers' activities become more significant when delivering blended or online courses and their role changes from knowledge deliverer to learning designer. Therefore, teachers are challenged to recognize new learning behaviour models and find new ways to engage and motivate learners. Universities offering study programs in blended or online way need to recognize learners' behaviour, know how to analyse the data, make it "understandable" to teachers and learners, and learn how to adapt course curriculum based on this data. Results of the case study conducted at Vytautas Magnus University revealed that after logging in to Moodle learning platform, students tend to spend time checking forums or course assignments rather than browsing another course content. Moreover, a significant drop-out rate was noticed after the $4^{\text {th }}$ click, when $24 \%$ of students tend to quit the session. The results of this research confirm the fact that online learners' behaviour is changing rapidly, and teachers should be aware of that, understand preferred learning patterns and develop course content based on this data.

\section{Theoretical background}

Online learning platforms like MOOCs and Moodle access and collect large amounts of data allowing to observe and analyse learners' interaction, behaviour and engagement into study process at macro and micro levels. When engaging in online or blended courses, learners have various intentions and experiences, and therefore they demonstrate different learning behaviours. To recognise learning behavioural patterns, teachers aim to master how to access the data, understand it, rethink course content based on this data and improve curriculum. Learning analytics help to understand and optimise learning processes and environments where this learning happens. Moreover, it could also help to measure learners' engagement, suggest study materials and resources based on test results, personalise learning experiences, provide feedback for the submitted work (Radu, 2017) and encourages teachers' metacognition related to their teaching practice. LA serves as a metacognitive tool encouraging and allowing teachers to improve the way they teach and organise their teaching, 
helping students to learn and monitor their learning process. These decisions and observations could be made by using structured analysis techniques.

LA can provide evidence of students' learning performance and behaviour in educational settings and consequently teaching strategies and instructional measures can be taken based on the presented facts. This also implies that such evidence will allow teacher to employ needed strategies and use personalized interventions as well more attention might be paid to low achievers. Learners' engagement in discussion forums and attendance of online lectures were found to be positively associated with each other, moreover, submissions to the discussion forums and amount of interaction online (Ellis, Han, \& Pardo, 2017) were directly related with a positive effect on learners' final exam grades.

These finding confirm that teachers' activities become more significant when both, recognising trends and challenges of learners' behaviour in online or blended course, or organising the learning and teaching curriculum by, for example, establishing a minimum reply requirement, drawing one's attention to others' ideas on a discussion topic, phrasing question in way motivates and engages as many students as possible (Kim et al., 2016). All these transformations of teachers' activities demonstrate their changing role, from being knowledge deliverer to becoming learning designer (Buckingham Shum \& Crick, 2016), being able to recognise learners' behaviours and respond to their learning needs.

\section{Learners' behavioural patterns in online courses}

When discussing learners' behaviour and engagement into online and blended courses, it is important to note, that open online or blended courses offer the unique possibility to uncover different and diverse student behaviours. And this is one of the significant aspects that differentiates open online courses from traditional courses (Anderson et al., 2014).

There are number of different categorisations and clusters identified based on various criteria related to learners' engagement with one or the other learning resource or task. Douglas et al. (2016) clustered learners into five groups based on their material usage: (a) fully engaged learners, with regular participation; (b) consistent viewers, who do not regularly access the course assessment materials (c) two-week engaged learners, participating first two weeks of the course (d) one-week engaged learners, who fully access the first week's materials and (e) sporadic learners who randomly access materials. Learners engagement into the course through video lectures and assignments for credits was observed by Anderson et al. (2014). As previous authors, they have identified 5 behavioural patterns which described learners as viewers (primarily watching videos; submitting only few assignments); solvers (primarily submitting assignments; watching few if any videos); all-rounders (equally engaging when watching videos and preparing assignments); collectors (primarily downloading video lectures but not necessarily watching them, presenting few assignments if any); and bystanders (signing up for the course but demonstrating extremely passive engagement). Other behavioural clusters like passive participants, active participants, community contributors (Koller, Ng, \& Chen, 2013), dropouts, excellent students, gamblers or learners who played with 


\section{Disclosing Learners' behaviour and Engagement into Online and Blended Courses: Case Study of Vytautas Magnus University \\ Giedrè Tamoliūnè et al.}

the system, and social learners (Khalil, Kastl, \& Ebner, 2016) demonstrate closely related features of learners' behaviour, although it is important to distinguish that they identify learners' need for socializing and networking. These learners tend to engage in course activities but they demonstrate specific interest in facilitating forum discussions or contributing and helping other learners by, e.g. providing foreign language subtitles (Koller, $\mathrm{Ng}$, \& Chen, 2013).

Based on these learning trends, Kim (2016) suggest to pay attention to encouragement of students before the mid-term by shifting from course related material to discussion and allowing learners to progress with more in-depth analysis and understandings in the class or team based discussions. Aiming to increase learners' engagement, Universities, together with administrators of virtual learning platforms and teachers, deployed a system of badges and conducted an experiment where this system was presented to different learners' subpopulations. Research results demonstrated that badge system had a positive impact on learners' participation and engagement (Anderson et al., 2014).

Thus, teachers should be able to understand how different measurement approaches could help them to monitor learning process and improve teaching process. Gašević, Dawson, and Siemens (2015) pointed out the important learning evidence possibilities to collect by observing completion of online quizzes or course grades, which did not accurately measure learning outcomes but rather academic performances at a given point in time.

To sum up, clustering can help to illustrate learners' profiles based on their behaviours, like time spent of doing and completing the assignment, test or other learning activity, group learning, or time of one's engagement into specific activity (Antonenko, Toy, \& Niederhauser, 2012; Dutt, Ismail, \& Herawan, 2017). Dutt, Ismail, and Herawan (2017) emphasize that regarding variety of methods and algorithms for data clustering, teachers and researchers should keep in mind their research aim and be very careful when choosing the most appropriate method for collecting valid data.

It is important to note, that despite the variety of data visualisation tools and huge amounts of statistical data, researchers (Gašević, Dawson, \& Siemens, 2015; Derr, 2017) are emphasizing the importance of qualitative studies in this field, which would give better understanding of learners' behaviour, e.g. through the texts created in discussions or blogs.

\section{Research methodology}

This study aims to present trends and challenges of learners' engagement into online and blended courses at Vytautas Magnus University. Desk research and interviews with teachers were conducted to collect data related to our research topic. Desk research was implement to recognise and observe which learning activities teachers tend to organise when delivering online or learning courses and how, what behavioural patterns can be recognised from macro level, etc. These observations and results were further validated and exploited with the 
empirical research based on semi-structured interviews with teachers, more in-depth analysis of their module curriculum and their metacognitive activities for curriculum redesigning.

\section{Findings}

This University offers traditional study courses mainly, although two online study programs are offered and delivered to learners worldwide. Other study programs are free to choose how study courses are delivered, i.e. face-to-face, blended or online courses. Even though teachers are not obliged to deliver blended or online courses, they are required to upload their courses on Moodle platform. Therefore, since 2013 when Rector's order was released, a significant growth of online study modules can be noted (see Figure 1)

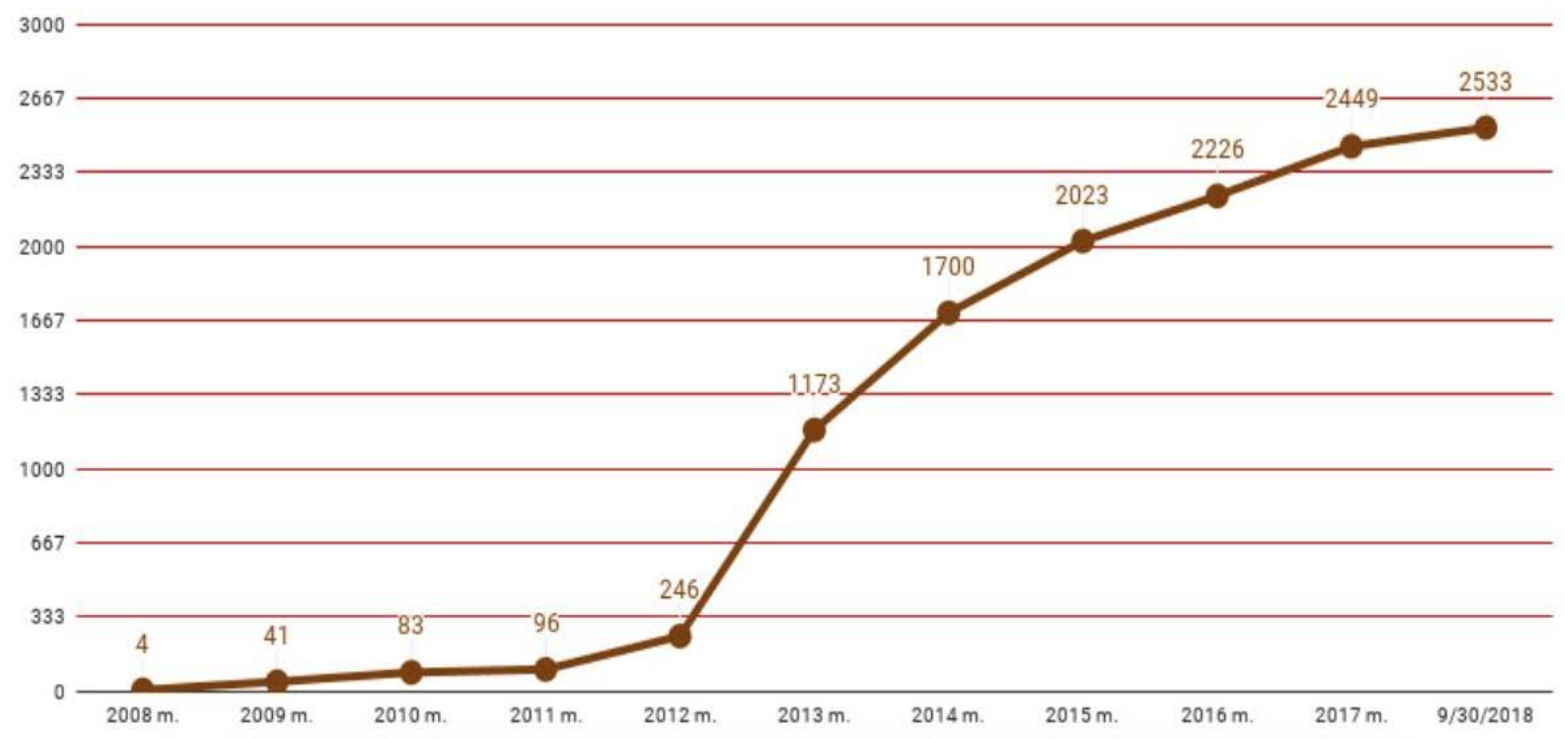

Figure 1. Number of online study modules at VMU

Until now there are 211 modules accredited as high quality blended courses on Moodle platform, and 101 courses are accredited and delivered fully online. Most of the fully online module are the ones delivered in online study programs, although there are some teachers from traditional study courses aim to modernize their modules and deliver it online.

When considering the variety of tools that are used by teachers in Moodle, the data reveal that forums and assignments have increased significantly since 2012 (see Table 1) and are much more elaborated than tools for, e.g. providing feedback or constructing mind-maps. The number of quizzes have increased significantly and it may reflect teacher's aim to engage students into the learning process.

Table 1: $\quad$ The use of Moodle learning activities

\begin{tabular}{lccccccc}
\hline Tool & 2012 & 2013 & 2014 & 2015 & 2016 & 2017 & 2018 \\
\hline Assignment & 1045 & 1465 & 2185 & 3069 & 4426 & 5824 & 6569 \\
Chat & 215 & 247 & 226 & 225 & 258 & 285 & 290 \\
Choice & 73 & 83 & 118 & 148 & 259 & 351 & 401 \\
Feedback & 20 & 33 & 90 & 100 & 152 & 191 & 257 \\
Forum & 1928 & 2884 & 4170 & 4772 & 5802 & 6526 & 6515
\end{tabular}




\begin{tabular}{|c|c|c|c|c|c|c|c|}
\hline Glossary & 190 & 229 & 232 & 249 & 257 & 286 & 319 \\
\hline Group choice & 8 & 38 & 47 & 78 & 140 & 199 & 210 \\
\hline HotPotatoes & 748 & 908 & 933 & 1085 & 1141 & 1286 & 1268 \\
\hline Mindmap & 12 & 37 & 53 & 79 & 155 & 165 & 134 \\
\hline Quiz & 922 & 1023 & 1092 & 1187 & 1568 & 1940 & 1939 \\
\hline Wiki & 56 & 73 & 156 & 187 & 234 & 252 & 270 \\
\hline Workshop & 38 & 55 & 71 & 89 & 66 & 71 & 62 \\
\hline Database & & & & & 45 & 66 & 76 \\
\hline
\end{tabular}

To increase learners' engagement and participation in learning activities, badge system has been introduced to teachers. Even though this, conditionally innovative motivation system has not been used over modules widely, there are some teachers who have integrated badges into their courses already.

All the above discussed tools and learning activities are organised by teachers who are willing to encourage learners to become active learners, participating in interactive activities, discussing in forums, monitoring their learning process and reflecting on it. Recent data of learners' behavioural flow reveal that students tend to check the course material in " 4 clicks" (see Figure 2). The significant drop-out rate was noticed after the $4^{\text {th }}$ click, when $24 \%$ of students tend to quit the session.

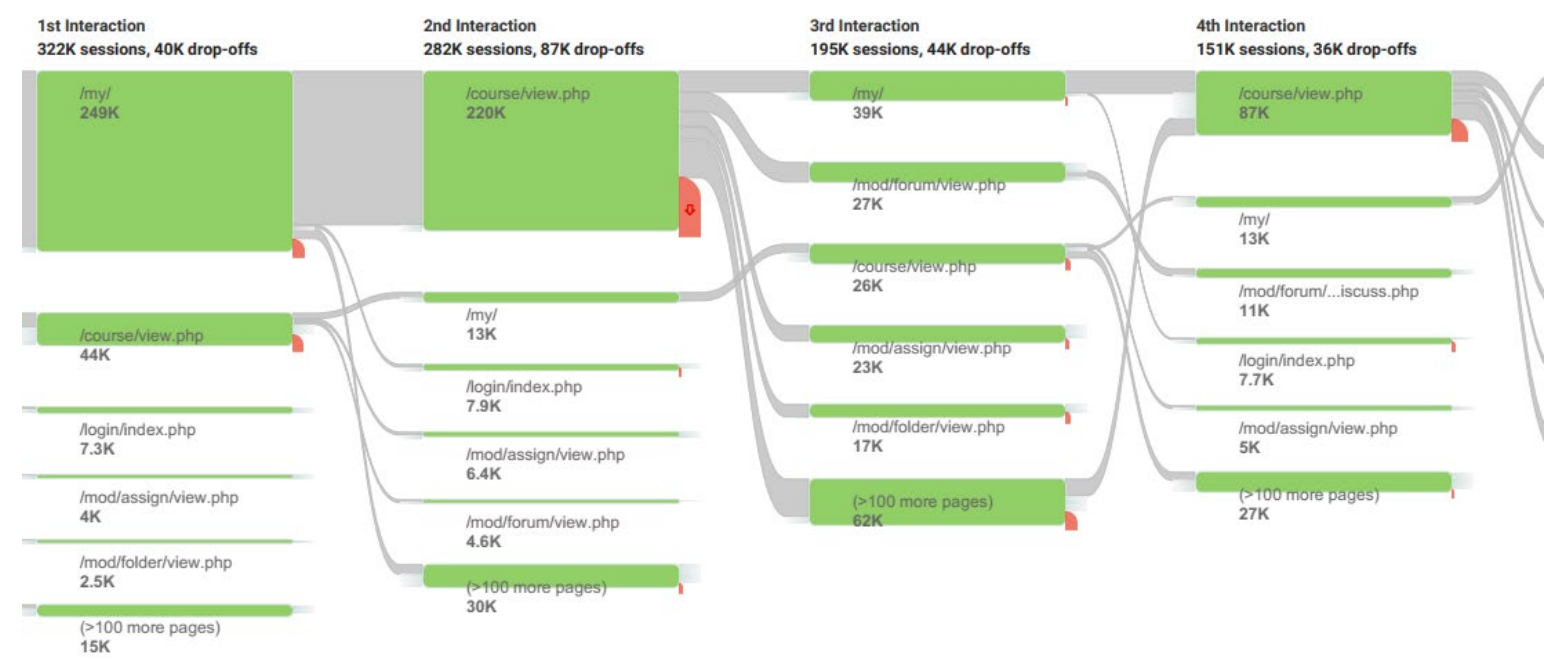

Figure 2. VMU learners' behavioural flow

The results of this research confirm the fact that online learners' behaviour has changed significantly as now part of the learners aim to receive information very quickly and in small pieces, without spending much time searching or reading additional learning resources. Teachers should be aware of that, understand these learning patterns and redesign their module curriculum based on this data. Despite the ongoing discussions about improvement of online or blended courses, in many occasions, there is a gap between knowing that a certain data about learners' behavioural patterns are significant and knowing how to make changes upon it encouraging their engagement into study process. 


\section{Conclusions}

When learning in a blended or online study courses, students demonstrate their need for an easily-absorbed information in small pieces. As data has shown, learners do no spend much time analysing course content, mainly focusing on the latest topic and news forum. For us, as researchers, this data analysis allowed to distinguish some aspects that our future research should focus on, e.g. how teachers apply LA data for their course improvement, do they recognise how this data should be monitored, what data do they monitor, and how they facilitate learners' discussions? To answer these questions, qualitative research will be conducted, providing a more in-depth and experience-based data on learners' behavioural patterns and teachers course organising reflecting these patterns.

\section{References}

Anderson, A., Huttenlocher, D., Kleinberg, J., \& Leskovec, J. (2014). Engaging with massive online courses. Proceedings of the $23^{\text {rd }}$ international conference on world wide web (WWW'14), 687-698. Retrieved from https://www.cs.cornell.edu/home/kleinber/www14courses.pdf

Antonenko, P. D., Toy, S., \& Niederhauser, D S. (2012). Using cluster analysis for data mining in educational technology research. Educational Technology Research and Development, 60(3),383-398. Retrieved from http://www.jstor.org/stable/41488590

Buckingham Shum, S., \& Crick, R. D. (2016). Learning Analytics for $21^{\text {st }}$ Century Competencies. Journal of Learning Analytics, 3(2), 6-21. https://doi.org/10.18608/jla.2016.32.2

Derr, K. K. (2017). Identifying Consistent Variables in a Heterogeneous Data Set: Evaluation of a Web-Based Pre-Course in Mathematics. Electronic Journal of E-Learning, 15(1), 8293. Retrieved from https://eric.ed.gov/?id=EJ1140127

Douglas, K. A., Bermel, P., Alam, M. M., \& Madhavan, K. (2016). Big Data Characterization of Learner Behaviour in a Highly Technical MOOC Engineering Course. Journal of Learning Analytics, 3(3), 170-192. https://doi.org/10.18608/jla.2016.33.9

Dutt, A., Ismail, M. A., \& Herawan, T. (2017). A Systematic review on educational data mining. IEEE Access, 5, 15991-16005. doi: 10.1109/ACCESS.2017.2654247

Ellis, R. A., Han, F., \& Pardo, A. (2017). Improving Learning Analytics - Combining Observational and Self-Report Data on Student Learning. Journal of Educational Technology \& Society, 20(3), 158-169. Retrieved from http://www.jstor.org/stable/26196127

Gašević, D., Dawson, S., \& Siemens, G. (2015). Let's not forget: Learning analytics are about learning. Techtrends: Linking Research \& Practice to Improve Learning, 59(1), 64-71. doi:10.1007/s11528-014-0822-x 
Khalil, M., Kastl, Ch., \& Ebner, M. (2016). Portraying MOOCs learners: A clustering experience using learning analytics. Proceeding of the European MOOC Stakeholder Summit 2016, 265-278. Retrieved from https://pure.tugraz.at/portal/files/3217512/komplette.265_278_1_.pdf

Kim, D., Park, Y., Yoon, M., \& Jo, I. (2016). Toward evidence-based learning analytics: Using proxy variables to improve asynchronous online discussion environments. Internet \& Higher Education, 30, 30-43. doi: 10.1016/j.iheduc.2016.03.002

Koller, D., Ng, A., \& Chen, Zh. (2013, June 3). Retention and intention in massive open online courses: In depth. Educause review [Blog post]. Retrieved from https://er.educause.edu/articles/2013/6/retention-and-intention-in-massive-open-onlinecourses-in-depth

Radu, I. R. (2017). Emergent technologies for learning analytics. Elearning \& Software for Education, 509-514. doi:10.12753/2066-026X-17-157

\section{Acknowledgments}

Preliminary findings presented in this study will serve as a basis for further empirical research conducted in the four year-long scientific research project "Open Online Learning for Digital and Networked Society" (3.3-LMT-K-712-01-0189). The financial support provided by the ESF and Lithuanian Research Council under High Level R\&D grant is gratefully acknowledged. 